\title{
Proceeding
}

10th INSHS International Christmas Sport Scientific Conference, 4-5 December 2015. International Network of Sport and Health

Science. Szombathely, Hungary

\section{Assessment of periodization training in soccer}

\author{
GAETANO RAIOLA ${ }^{1}$,TIZIANA D'ISANTO ${ }^{2}$ \\ 1 University of Parthenope, Naples, Italy \\ 2 University of Salerno, Salerno, Italy
}

\begin{abstract}
Football is a situation sport, which means the athletes are part of many dependents variables, such as field, climate conditionings, teammates, presence of ball and more. Aspects that significantly affecting the training in this sport are: conditional aspect, psychological and technical-tactical. In power words, Soccer is a sport about situation and therefore imposes high demands for technical skills and physical specifications that have to be continually stressed in training. Several key components affect the performance of athletes during the race. The thesis developed is the concept of periodization, that is the division of athlete's preparation in particular periods of time with well-defined objectives, it means the division of training season in specific periods in order to clearly defined goals. The research is made by two part, the first one is carried out with the data on 16 male athletes aged between 18 and 34 years of a football team to 11 enrolled in the championship of Campania region, with the use of physical tests for the evaluation of Resistance, Speed, Acceleration, measurement of body circumferences, height and weight. Periodization is a proposal for a Tudor Bompa and constitutes a methodological approach aimed at achieving the objectives of training required for competitive levels predetermined. The second one is characterized by High Intensity Intermittent Training (HIIT), such important in soccer as many team sports, characterized by phases of high oxygen consumption alternate by recovery series. The study is conducted on a sample of 20 male Soccer players of $16.8 \pm 1$ years old members of a Sub-18 team of Italian National League "Beretti". The athletes were divided into two groups according to their results of aerobic power detected by the Cooper test carried out at the beginning of the preparatory period: a group working with an higher internal load $(90 \% \mathrm{HR})$, and another group performing the same, but holding a lower one ( $80 \% \mathrm{HR}$.). That division was made in such a way as to obtain the desired adaptations and improvements in both groups, because having different characteristics, and in such a manner as to not create high overloads that, producing lactate they would prevent the adaptations and improvements sought. This study shows us how the intermittent training leads to a significant
\end{abstract}

Corresponding author. via Berenice 11, Napoli, Italy

E-mail: raiolagaetano@libero.it

10th INSHS International Christmas Sport Scientific Conference, 4-5 December 2015. International Network of Sport and Health Science. Szombathely, Hungary.

JOURNAL OF HUMAN SPORT \& EXERCISE ISSN 1988-5202

(c) Faculty of Education. University of Alicante

doi:10.14198/jhse.2016.11.Proc1.19

VOLUME 11 | Proc1 | 2016 | S267 
increase in VO2max. The research takes into account the different phases of training annually monitored for a period of 4 months using 4 measurements of physical tests. The data collected will have to demonstrate an improvement in the ability of conditional force in order to reach the peak performance of the variables under consideration within the period. The data collected were subjected to a statistical study that showed improvements in physical performance of the different athletes thanks to the use of Periodization method integrated to High Intensity Intermittent Training. Significant, according to the method of periodization, the gradual increase of the applied load which allows the central nervous system (CNS) to adapt and achieve improvements. The aim of this study was to compare effects and improvements of an HIIT in two groups of Youth Soccer Players with different fitness characteristics, monitoring the Maximum Oxygen Consumption (VO2max) as parameter of internal load. Key words: HIIT, VO2 MAX, QUANTITATIVE TEST, STRENGHT, PEAK PERFORMANCE, PROGRESSIVE LOAD. 


\section{INTRODUCTION}

Soccer is a high-situational sport with a high agonistic engagement such to require the development of all the conditional capacities. The training approach is different among individual sport and team sport and games sport; for example in water sport the training is addressed to specific part of the peak performance (Napolitano et al, 2013abc, Tursi et al 2013a)). Otherwise, in volleyball the training process have to include individual aspects (Parisi, Raiola 2014ab, Raiola et al 2016c) and collective one (Raiola et al, 2013c, Raiola, 2012, Raiola, Di Tore 2012abc). Video analysis in futsal is a tool to training and so, it becomes a tool to enlarge the planning of sports skills and drills (Polidoro et al, 2013, Tursi et al, 2013b). Coaches need to understand the specific technical skills and tactics required by their sport and then to follow the suggestions and the indications of the most current methods of training in order to maximize the potential of the players. In basketball, similar soccer for strategic and tactical team, training is made by quantitative and qualitative part to mix in a holistic dimension (Raiola et al, 2016ab) and the resulting optimal running technique and tactics of individual team. According to Tudor Bompa (2009) achieving the best run of form by athletes in team sports, it must be through a targeted workout methodology, rather than through the practice of the game, instead favor an approach that many coaches. The models of training are intended to simulate or reproduce the elements of a real game situation with the intent of enhancing the effectiveness of the team in specific situations and against specific opponents and to study on effects of hiit-high intensity intermittent training in soccer players (Gaetano, Rago, 2014). "Mold" means, therefore, create training programs that reproduce the technical, tactical and psychological aspects of competition and training schedule based on teams that you will encounter (Gaetano et al., 2015ab). As already mentioned, football is a sport high situational then necessarily have to train all three aspects of performance, technical, tactical together at organic muscle aspects. Coaching for example only conditional aspects would be detrimental in a sport like soccer in which successive quick actions and technical tactical actions, which means motor control and learning (Raiola 2014, Raiola et al, 2014, Raiola, 2011ab), such as in aerobic and gymnastic (Raiola et al 2013ab).

The model of training prepares the players according to the specific meeting, the strengths and weaknesses of the opponent, the climatic conditions and social environments in which the race will take place. Tudor Bompa is often regarded as the father of periodization theory, a training system developed by the soviets that emphasized on variable loads for optimal performance throughout the year rather than maintaining a constant training focus. Also, motor control and learning could have the same role in performance especially in qualitative aspects of movement (Raiola, 2012, 2014ab, 2015). Qualitative aspects of performance doesn't investigated in correlation to quantitative one, though it is necessary to asses and to plan training activity (Raiola et al, 2016abcd). Furthermore, virtual representation and its utilization in training with exergames model could be a complementary field to increase the performance (Di Tore, Raiola, 2012abc).

Periodization The term refers to two important aspects: the periodization of the Annual Plan, which allows you to split and manage the training program and to achieve maximum shape for the biggest races, and the Periodization of Motor Capacity conditionals or organic-muscle, which allows you to carry at an optimum level skills conditional, such as strength, speed and endurance.

Periodization for the annual plan means the annual organization of training in phases, so as to:

- manage the process of training more easily;

- have the peak of form in conjunction with the most important races; 
- prevent injuries;

- avoid overtraining (Raiola, Tafuri, 2015abc).

In soccer, the postural aspects and the relationship to teaching method for training could play a role in performance (Raiola et al, 2015), it has to consider to increase the drills.

Periodization in team sports come so divided:

1) Period introductory or pre-season preparation that provides strong valence organic and muscle recovery overall efficiency.

2) Period or critical load, where the volume of work prevails on the intensity of the same. Be expected during the break times in the league or in conjunction with lots of secondary importance. The acquisition of technical skills will be more difficult for a possible condition of fatigue. the main objective of this phase is to develop the highest possible level of strength.

3) Period or special processing to increase the intensity of work and to develop a growing technical work.

4) Competitive Period: This is the time when you have the achievement and maintenance of maximum fitness during the most important races.

5) Period of transition coincides with the long break between one season and the other to regenerate the body.

The aim is to verify the improvements after the conditional period of training and testing of the moment of maximum performance (peak performance) over the time period under evaluation.

Is common knowledge that a certain athlete, after years of training, despite continuing to practice, reaches a stabilization of performance and certain cardiovascular parameters, such as maximum oxygen consumption (VO2max). Then, the work of the fitness coach becomes even more complex, to obtain a further increase in performance, will be necessary to maximize the modifications obtained through training with an optimal modulation of the loads, that is, reach the maximum level tolerable by the organism without getting "overtraining".

The intermittent exercise determines an improvement of $\mathrm{VO} 2$ max in athletes who already have good aerobic fitness as it is a good training means to maintain high levels of aerobic power, especially in reference to the stimulus that it determines to the central components; the increase of aerobic enzyme, as reported in some studies, seems to be caused by the necessity of the fibers to metabolize lactate and by a flow increase of pyruvate within the mitochondria (Hill-Hass, et al. 2009). This would explain the increase of oxidative capacity measured in type II fibers observed in the past study of many authors; intermittent drills can result in increased glycolytic characteristics and ability to perform maximum efforts (Randers, et al. 2010, Rebelo, et al., 2012). This study is based on the method of Periodization Training that refers to two important aspects: Periodization of the Season Plan, which allows players to split and manage the training program and to achieve maximum fitness for the most important games, Periodization of Motor-Conditional Skills which allows players to lead to an optimal level of conditional skills, such as strength, speed and endurance. Periodization according to Tudor Bompa and Haff Gregory G (2009) in team sports come divided as follows:

1) Introductory/Preparatory period that focus on strong organic valence and muscular for the recovery of overall efficiency. In this period we carried out an initial test for the division of the two training groups.

2) Key/Load period where the working volume prevails on the intensity of that. At this stage, we carried out the Cooper test once again in order to estimate the improvements caused by IT. 
3) Special/Transformation period to increase the intensity of drills and to develop a increasing technical work.

4) Competitive Period where there is the achievement and maintenance of maximum fitness at the time of most important games.

5) Transition period is the long break between two seasons that allows the organism to regenerate.

Training process of periodization paradigm and other theory have to be systematized in a protocol and battery testing in a context of soccer (Hoff, Helgerud, 2004, Little, Mohr et al, 2005, Williams, 2007).

To aim firstly to compare effects and improvements of an HIIT in two groups of Youth Soccer Players with different fitness characteristics, monitoring the Maximum Oxygen Consumption (VO2max) as parameter of internal load.

To aim secondly to verify the improvements after the conditional period of training and testing of the moment of maximum performance over the time period under evaluation. To aim on second investigation is to deep aspects of HIIT in two groups of Youth Soccer Players with different fitness characteristics, monitoring the Maximum Oxygen Consumption (VO2 $\mathrm{max}$ ) as parameter of internal load. Synthetically, to get in relationship to other aspects to project a model training in soccer to aim the drills development.

\section{MATERIAL AND METHODS}

The approach of investigation is developed in twice ways. The first study is conducted according the following steps. During the various stages of periodization, the goal will be to improve both the appearance conditional progressively increasing workloads, both the technical and tactical exercises introducing eco - dynamics aiming at reproducing the context of race. This type of exercises, unlike those that refer to a cognitive approach, intended to improve the capacity of choice for athletes, who will meet from time to time to cope with different situations. In this research, we will discuss only the quantitative aspects. The tests will be carried out: At the beginning of the preparatory period the end of the loading period and at the end of the processing period (which coincides with the beginning of the period agonistic).

The tests that will be carried out are:

1) Measurement of body circumferences.

2) Calculate VO2max; V.A.M. and S.AN (via test Lèger shuttle 20m).

3) Bench press Test.

4) Weight and height.

The second study is conducted on a sample of 20 male Soccer players of $16.8 \pm 1$ years old members of a Sub-18 team of Italian National League "Beretti".

The athletes were divided into two groups according to their results of aerobic power detected by the Cooper test carried out at the beginning of the preparatory period, during the Pre-season.

The players who were included in the 1st group of work (Cooper Test $=2850 \pm 150$ meters) were 12 , then subjected to a higher internal load training ( $90 \% \mathrm{HR})$, also the remaining 8 members of 2nd group of work (Cooper Test $=2500 \pm 100$ meters) were subjected to a lower internal load training $(80 \% \mathrm{HR})$.

Why this division? The division was done in such a way as to obtain the desired improvements and adaptations in both groups for two reasons: 
1) The members of 1 st group of work, if they had worked at about $80 \% \mathrm{HR}$ of internal load they probably would have done just a maintenance drill VO2max without getting increase of it.

2) The members of 2 nd group of work, 2 if they had worked at about $90 \%$ of internal load, they would have obtained a lactate hyperproduction that would have prevented the beneficial adaptations of HIIT.

The High-Intensity Intermittent Training was applied during the Load period equivalent to 8 weeks of Season Plan. At the end of the Load period was carried out the Cooper once again test to estimate the improvements obtained through this methodology.

Finally, the two studies are in the same discussion and conclusion to merge synthetically the training applications.

\section{RESULTS AND DISCUSSION}

The expected results, are expected to increase at least $9 \%$ of the variables under consideration, which would be an important result because we are talking about professional athletes that even in times of transition is not greatly reduce their level of performance.

Table 1. Data Athletes

\begin{tabular}{ccccccc}
\hline Athlete & Role & Weight Kg & Height cm & Waist & Quadriceps & BMl \\
\hline 1 & MF & 78 & 176 & 85 & 54 & 22,15 \\
2 & MF & 80 & 181 & 85 & 54 & 22,09 \\
3 & FW & 65 & 170 & 81 & 50 & 21,38 \\
4 & MF & 73 & 176 & 79 & 48 & 20,73 \\
5 & SB & 69 & 168 & 78 & 45 & 20,53 \\
6 & MF & 72 & 183 & 80 & 51 & 19,67 \\
7 & SB & 71 & 175 & 77 & 50 & 20,28 \\
8 & SB & 75 & 178 & 79 & 56 & 21,06 \\
9 & CB & 75 & 185 & 80 & 52 & 20,27 \\
10 & CB & 79 & 182 & 84 & 58 & 21,70 \\
11 & MF & 70 & 175 & 72 & 47 & 20 \\
12 & FW & 84 & 181 & 90 & 52 & 23,20 \\
13 & FW & 80 & 185 & 86 & 53 & 21,62 \\
14 & FW & 61 & 171 & 75 & 48 & 17,83 \\
15 & SB & 75 & 175 & 80 & 54 & 21,42 \\
16 & CB & 80 & 180 & 80 & 50 & 22,22 \\
\hline
\end{tabular}


Table 2. VO2max; S.AN ; V.A.M.

\begin{tabular}{cccc}
\hline ATHLETE & VO2 max & S.AN $(\mathrm{Km} / \mathrm{h})$ & V.A.M. $(\mathrm{Km} / \mathrm{h})$ \\
\hline 1 & 53,25 & 12,56 & 15,21 \\
2 & 52,32 & 12,2 & 14,82 \\
3 & 51,97 & 12,1 & 14,84 \\
4 & 50,96 & 12 & 14,56 \\
5 & 50,85 & 11,98 & 14,53 \\
6 & 50,85 & 11,98 & 14,53 \\
7 & 50,63 & 11,91 & 14,47 \\
8 & 50,05 & 11,76 & 14,37 \\
9 & 50,04 & 11,75 & 14,36 \\
10 & 49,37 & 11,65 & 14,03 \\
11 & 49,05 & 11,56 & 14 \\
12 & 48,72 & 11,47 & 13,91 \\
13 & 48,61 & 11,43 & 13,88 \\
14 & 47,74 & 11,27 & 13,65 \\
15 & 47,67 & 11,17 & 13,62 \\
16 & 47,27 & 11,16 & 13,62 \\
\hline
\end{tabular}

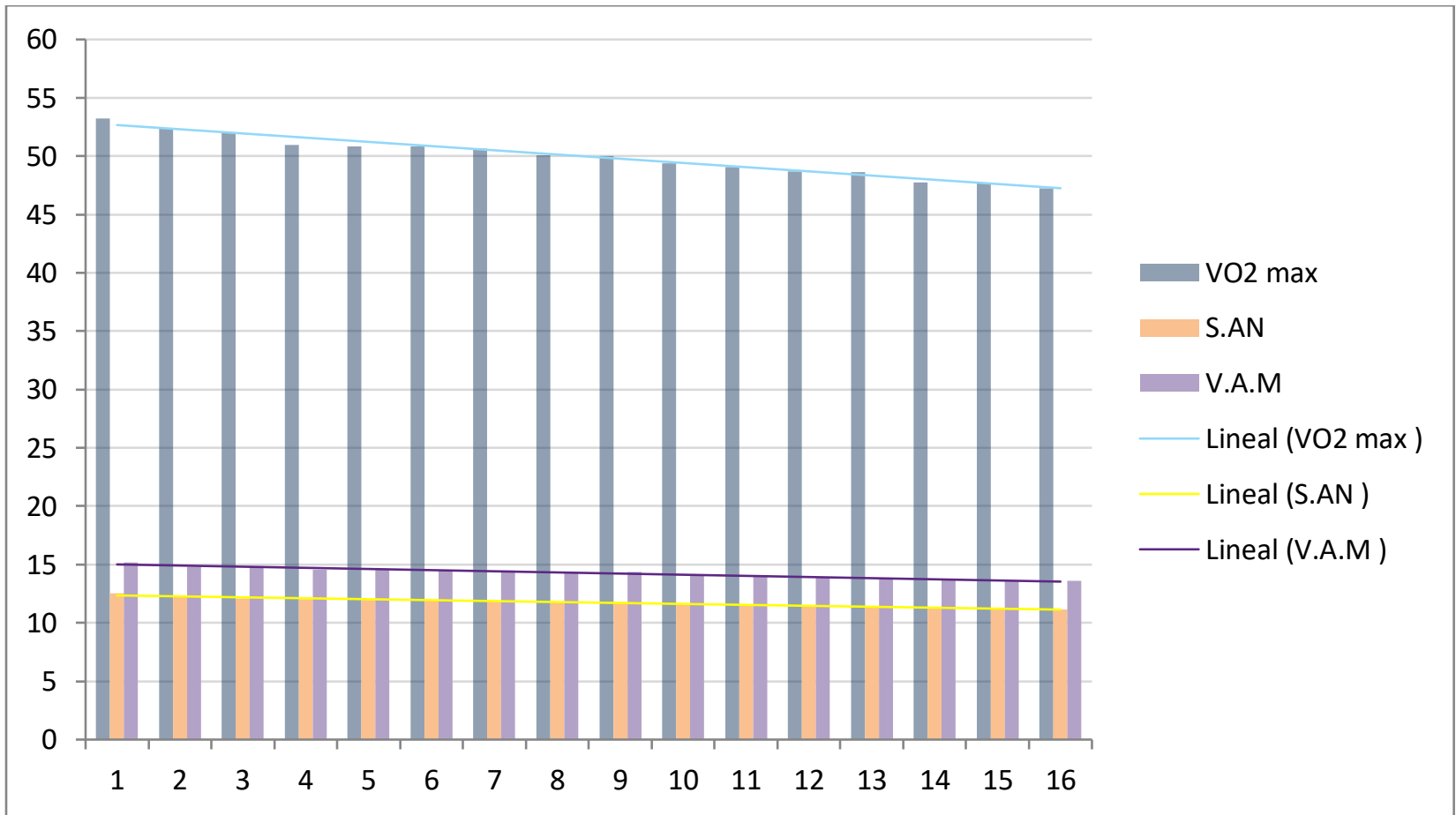

Figure 1. VO2max; S.AN ; V.A.M. 
Table 3. Bench Press test

\begin{tabular}{cccc}
\hline WEIGHT ATHLETE & RAISED KG & VALUE OF REFERENCE & RESULT \\
\hline 78 & 64 & 0,82 & INSUFFICIENT \\
80 & 65 & 0,82 & POOR \\
65 & 48 & 0,74 & INSUFFICIENT \\
73 & 61 & 0,83 & INSUFFICIENT \\
69 & 55 & 0,8 & INSUFFICIENT \\
72 & 64 & 0,9 & POOR \\
71 & 69 & 0,97 & MEDIUM \\
75 & 70 & 0,93 & MEDIUM \\
75 & 67 & 0,89 & MEDIUM \\
79 & 64 & 0,81 & POOR \\
70 & 58 & 0,83 & INSUFFICIENT \\
84 & 70 & 0,83 & INSUFFICIENT \\
80 & 65 & 0,81 & POOR \\
61 & 45 & 0,73 & INSUFFICIENT \\
75 & 61 & 0,81 & INSUFFICIENT \\
80 & 68 & 0,85 & INSUFFICIENT \\
\hline
\end{tabular}

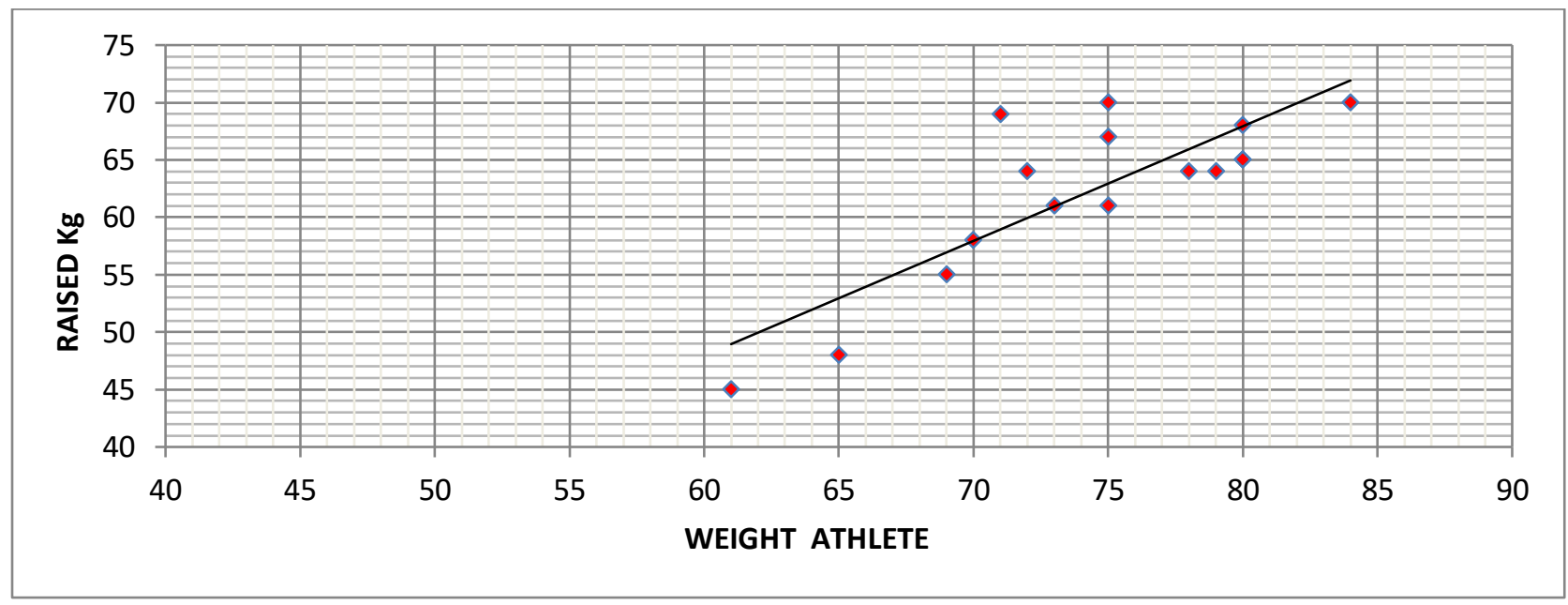

Figure 2. Bench Press test

It shows us how the intermittent training leads to a significant increase in VO2max.

From the results obtained is noted as there are no large improvements achieved by both groups, but the most marked improvements were recorded $2^{\circ}$ group who performed with a lower external load. 


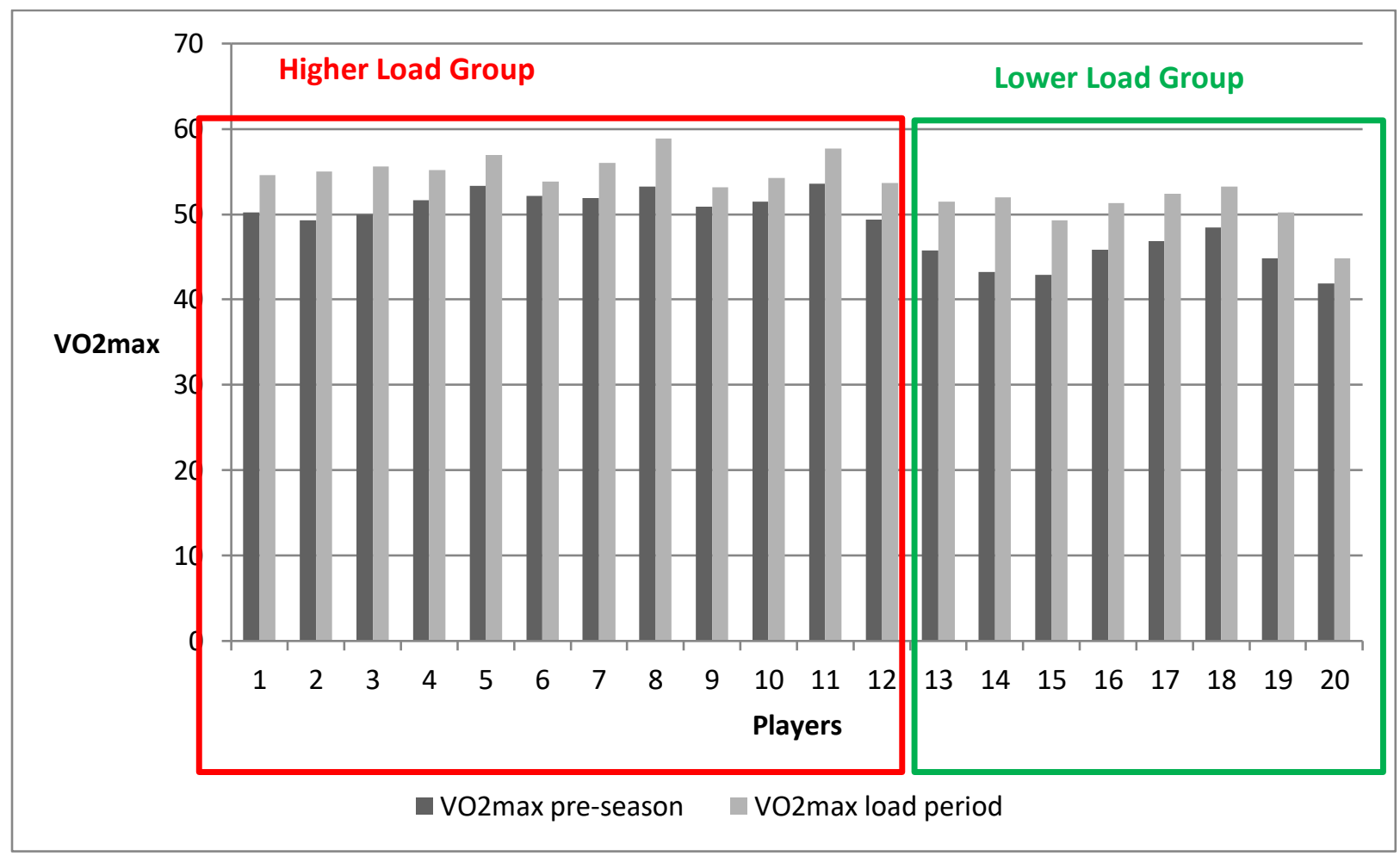

Figure 3. VO2max pre-season and load period

\section{CONCLUSIONS}

For ease of reading, the results of the planning of training with the method of periodization, will be converted to statistical data from which shows the trend of physical performance in the different training periods and in particular the peak performance. Peak performance has this expression maximum when also the qualitative aspects is at the top in relationship to the better skills in term of technical aspects of significate part of execution model of its (Altavilla, Raiola, 2014, 2015, Altavilla et al. 2015ab, Guetano et al 2015). This usually matches in football, as well as in games sport, and it is named competitive period. Influence of sports on the control and some aspects on teaching and learning are the basis of good performance (Altavilla et al. 2014ab). The qualitative aspects of motor coordination (Gaetano et al 2015ab) and sports game must be treated in the same way of quantitative aspects if it considers the physical activity and sport performance in a holistic vision; thus, it has to think in ecological approach way (Raiola 2014).

Finally, the goal is to support the Bompa method about the periodization in training for strength development, confirming theories and assuming new variables to be tested in order to improvements in athletic performance, in relationship to all other parameters of sport performance.

Performance in sports activity have to develop in early age in educate program of physical education (Raiola 2011, Di Tore, Raiola 2012ab).

The data collected were subjected to a statistical study that showed improvements in physical performance 
of the different athletes thanks to the use of Periodization method integrated to High Intensity Intermittent Training.

Significant, according to the method of periodization, the gradual increase of the applied load which allows the central nervous system (CNS) to adapt and achieve improvements.

Probably, the players of 1 st group had a higher lung volume to endure and achieve certain levels of $\mathrm{VO} 2$ max. The players of the 2nd group, performed HIIT drill in a lower speed than the 1st group, therefore resulted also a lower external load in terms of distance covered and maximum speed reached.

The objective of these twice study was to give more credit to the HIIT, as this drills produces adaptations of aerobic system useful to bearing match efforts and the correlation on skill son qualitative aspects about technical skills (Raiola, 2012ab, 2014). Contemporary, the second study carries out the periodization classic data to confirm the validity of Bompa method. The research sets the stage for future new investigations that they can research new methodologies in quantitative terms for the improvement of aerobic fitness, to be complemented with technical and tactical drills, thereby integrating, also qualitative contained.

\section{REFERENCES}

1. Altavilla, G., Raiola, G. (2015). Sports game tactic in basketball, Sport Science, 8(1).

2. Altavilla, G., Furino, F., Marika, D., Raiola, G. (2015a). Physical skills, sport learning and socioaffective education, Sport Science, 8, 1 supplement.

3. Altavilla, G., Furino, F., Di Palmo, M., Raiola, G. (2015b). The child hypokinetic and the over trained, Sport Science, 8, 1 supplement.

4. Altavilla, G., Raiola, G., (2014), Global vision to understand the game situations in modern basketball, Journal of Physical Education and Sport, 14(4).

5. Altavilla, G., Tafuri, D., Raiola, G., (2014a). Some aspects on teaching and learning by physical activity, Sport Science, 7(1).

6. Altavilla, G., Tafuri, D., Raiola, G., (2014b). Influence of sports on the control of static balance in physical education at school, Journal of Physical Education and Sport, 14(3).

7. Bompa, T.O., Haff Gregory, G. (2009). Periodization. Theory and methodology of training, 5th Edition, Human Kinetics.

8. Di Tore, P.A., Raiola, G. (2012a). Exergame-design and motor activities teaching: An overview of scientific paradigms on motor control, Mediterranean Journal of Social Sciences, 3(11).

9. Di Tore, P.A, Raiola, G. (2012). Case study on physical education and sport in Naples, Mediterranean Journal of Social Sciences, 3(11).

10. Di Tore, P.A., Raiola, G. (2012c). Exergames in motor skill learning, Journal of Physical Education and Sport, 12(3), 358-361.

11. Gaetano, R., Domenico, T., Gaetano, A. (2015a). Physical activity and its relation to body and ludic expression in childhood, Mediterranean Journal of Social Sciences, 6(3).

12. Gaetano, R., Gomez, F.P., Gaetano, A. (2015b) Anxiety in the youth physical and sport activity, Mediterranean Journal of Social Sciences, 6(3).

13. Gaetano, R., Rago, V. (2014). Preliminary study on effects of hiit-high intensity intermittent training in youth soccer players. Journal of Physical Education and Sport, 14(2), 148-150.

14. Guetano, R, Lipoma, M., Tafuri, D. (2015). Postural control in young soccer players: differences between the cognitive approach and ecological-dynamic one, Journal of Human Sport and Exercise, 10(1). 
15. Hill-Hass, S., Dawson, B., Coutts, A., Roswell, C. (2009). Physiological responses and time-motion characteristics of various small-sided soccer games in youth players, Journal of Sport Sciences, 27 (1).

16. Hoff, J., \& Helgerud, J. (2004). Endurance and strength training for soccer players: physiological considerations. Sports Medicine, 34(3).

17. Little, T., \& Williams, A. (2007). Measures of exercise intensity during soccer training drills with professional soccer players. Journal of Strength and Conditioning Research, 21(2).

18. Mohr, M., Krustrup, P., \& Bangsbo, J. (2005). Fatigue in soccer: a brief review. Journal of Sports Sciences, 23(6).

19. Napolitano, S., Di Tore, P.A., Raiola, G. (2013a). High diving: Evaluation of water impact and considerations on training methods. Journal of Human Sport and Exercise, 8(2).

20. Napolitano, S., Tursi, D., Di Tore, P.A., Raiola, G., (2013b). Tactics -based on waterpolo training, Journal of Human Sport and Exercise, 8(2).

21. Napolitano, S., Tursi, D., Raiola, G. (2013c). Waterpolo women's pattern tactical experience of an Italian team, Journal of Human Sport and Exercise, 8(3).

22. Parisi, F., Raiola, G. (2014a). Video analysis in youth volleyball team, Journal of Human Sport and Exercise, 9(1).

23. Parisi, F., Raiola, G. (2014b). The serve in under 12-13 Italian volleyball team, Journal of Human Sport and Exercise, 9(1).

24. Polidoro, L., Bianchi, F., Di Tore, P.A., Raiola, G. (2013). Futsal training by video analysis, Journal of Human Sport and Exercise, 8(2).

25. Raiola, G., Altavilla, G., Di Tore, P.A. (2016a). Analysis on some aspects of the service in volleyball, Sport Science, 9(1).

26. Raiola, G., Tafuri, D., Lipoma, M. (2016b). Teaching method indication for education and training of sport skills, Mediterranean Journal of Social Sciences,7(2).

27. Raiola, G., Tafuri, D, Lipoma, M. (2016c). Some aspects of gait analysis in educational vision, Mediterranean Journal of Social Sciences, 7(2).

28. Raiola, G., Altavilla, G., Tafuri, D., Lipoma, M. (2016d). Analysis of learning of shot in basketball, Journal of physical education, 5(1).

29. Raiola, G., Tafuri, D., Lipoma, M. (2016a). Teaching method indication for education and training of sport skills, Mediterranean Journal of Social Sciences, 7(2).

30. Raiola, G., Altavilla, G., Tafuri, D., Lipoma, M. (2016b). Analysis of learning of shot in basketball, Journal of physical education.

31. Raiola, G., Altavilla, G., Di Tore, P.A. (2016c). Analysis on some aspects of the service in volleyball, Sport Science, 9(1).

32. Raiola, G., Tafuri, D. (2015a). Pilot work on training for quantitative aspects of performance, Sport Science, 8(2).

33. Raiola, G., Tafuri, D. (2015b). Teaching method of physical education and sports by prescriptive or heuristic learning, Journal of Human Sport and Exercise, 10, 1 supplement.

34. Raiola, G., Tafuri, D. (2015c) Assessment and periodization in amateur soccer team, Sport science, 8 , supplement 2.

35. Raiola, G., Lipoma, M., Tafuri, D. (2015). Postural control in young soccer players: differences between the cognitive approach and ecological-dynamic one, Journal of Human Sport and Exercise, 10, 1 supplement.

36. Raiola, G., Scassillo, I., Parisi, F., Di Tore, P.A. $\left(2013^{\circ}\right)$. Motor imagery as a tool to enhance the didactics in physical education and artistic gymnastic, Journal of Human Sport and Exercise, 8(2). 
37. Raiola, G., Giugno, Y., Scassillo, I., Di Tore, P.A. (2013b). An experimental study on Aerobic Gymnastic: Performance analysis as an effective evaluation for technique and teaching of motor gestures, Journal of Human Sport and Exercise, 8(2).

38. Raiola, G., Parisi, F., Giugno, Y., Di Tore, P.A. (2013c). Video analysis applied to volleyball didactics to improve sport skills, Journal of Human Sport and Exercise, 8(2).

39. Raiola, G. (2012). Bodily communication in volleyball between human and experimental sciences, Mediterranean Journal of Social Sciences, 3.

40. Raiola, G. (2014). Motor control and learning skills according to cognitive and ecological dynamic approach in a vision on behaviorism, cognitive, gestalt and phenomenology theories, Mediterranean Journal of Social Sciences, 5.

41. Raiola, G., Tafuri, D., Paloma, G. (2014). Physical activity and sport skills and its relation to mind theory on motor control, Sport Science, 7(1).

42. Raiola, G., Di Tore, P.A. (2012a). Statistical study on bodily communication skills in volleyball to improve teaching methods, Journal of Human Sport and Exercise, 7(2).

43. Raiola, G., Di Tore, A. (2012b). Non-verbal communication and volleyball: A new way to approach the phenomenon, Mediterranean Journal of Social Sciences, 3.

44. Raiola, G., Di Tore P.A. (2012c). Bodily communication skills and its incidence on female volleyball championship to enhance didactics, Journal of Human Sport and Exercise, 7(1).

45. Raiola, G. (2011). A study on Italian primary school rules: Neurophysiological and didactics aspects on physical education and sport, Journal of Physical Education and Sport, 11(2).

46. Raiola, G. (2011) Study between neurophysiological aspects and regulation documents on preschool in Italy, Journal of Physical Education and Sport, 11(1).

47. Randers, B., Nyb, L., Nielsen, J., Christiansen, L., Bendiksen, M., Bangsbo, J., Krustrup, P. (2010). Activity profile and physiological response to football training for untrained males and females, elderly and youngster: influence of the number of players, Scand. J. Med. Sci. Sports.

48. Rebelo, A., Brito, J., Seabra, A., Oliveira, J., Drust, B., \& Krustrup, P. (2012) A new tool to measure training load in soccer training and match play. International Journal of Sports Medicine.

49. Tursi, D., Napolitano, S., Di Tore, P.A., Raiola, G. (2013a). Arm stroke: A comparative analysis between competitive swimming and water polo athletes, Journal of Human Sport and Exercise, 8(2).

50. Tursi, D., Napolitano, S., Polidoro, F, Raiola, G. (2013b). Video analysis as an instrument in juvenilia soccer training, Journal of Human Sport and Exercise, 8(3). 